Connotas. Revista de crítica y teoría literarias 


\begin{tabular}{|ll|}
\hline PQ6001 & Connotas. Revista de crítica y teoría literarias / \\
Director Fortino Corral Rodríguez.-Hermosillo, Sonora: \\
unIson. Departamento de Letras y Lingüística. \\
C2011. \\
V-: $23 \mathrm{~cm}$. \\
Semianual \\
Año VII, No. $12(2011)$ \\
ISSN: 1870-6630 \\
Incluye bibliografía. \\
1. Literatura española - Historia y crítica-Publicaciones \\
periódicas. 2. Literatura hispanoamericana - Publicaciones \\
periódicas. I. Corral Rodríguez, Fortino, dir.
\end{tabular}

CONNOTAS. REVISTA DE CRÍTICA Y TEORÍA LITERARIAS. Año VII, núm. 12, enero junio 2011, es una publicación semestral editada por la Universidad de Sonora, a través de la División de Humanidades y Bellas Artes, en el Departamento de Letras y Lingüística. Blvd. Luis Encinas y Blvd. Rosales s/n, Col. Centro, C.P. 83000, Hermosillo Sonora; Tel. (662) 2592 136, (662) 2592 157, <www.uson.mx>, <http://www.connotas.uson.mx, connotas@capomo.uson.mx>. Editor responsable: Rosario Fortino Corral Rodríguez. Reservas de Derechos al Uso Exclusivo núm. 04-2006-020714184900-102. ISSN: 1870 6630; ambos otorgados por el Instituto Nacional del Derecho de Autor. Licitud de Título núm. 13434 y de Contenido núm. 11007, otorgados por la Comisión Calificadora de Publicaciones y Revistas Ilustradas de la Secretaría de Gobernación. Impresa en Impresos RM S.A. de C.V., Privada Miguel Alemán no. 17, col. San Benito, Hermosillo, Sonora, México. Tel. 2 100212, e-mail impresosrm@gmail.com. Este número se terminó de imprimir el 5 de octubre de 2011 con un tiraje de 300 ejemplares. Las opiniones expresadas por los autores no necesariamente reflejan la postura del editor de la publicación.

Se autoriza la reproducción total o parcial de los contenidos de la presente publicación, siempre y cuando se acredite adecuadamente el origen de los mismos.

Este número se publicó con apoyo del Programa Integral de Fortalecimiento Institucional

Datos de contacto para la publicación: División de Humanidades y Bellas Artes, Departamento de Letras y Lingüística; Apartado Postal 793, Col. Centro, C.P. 83000, Hermosillo, Sonora, México. Tels.: (662) 259-21-87, Tel-fax 212-55-29. Correo electrónico: connotas@capomo.uson.mx Página web: http://www.connotas.uson.mx 


\section{Connotas. Revista de crítica y teoría literarias}

Año VII / Núm. 12 / Enero-junio 2011

COMPILAdOR DE ESTE NÚMERO

César Avilés Icedo

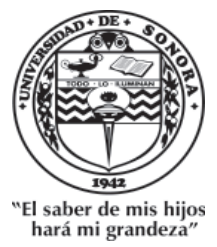

UNIVERSIDAD DE SONORA 


\section{UNIVERSIDAD DE SONORA}

RECTOR

Heriberto Grijalva Monteverde

VicerReCTORA

Arminda Guadalupe García de León Peñúñuri

Secretario General Académico

Enrique Fernando Velázquez Contreras

División de Humanidades y Bellas Artes

María Rita Plancarte Martínez

DePARTAMENTO DE LETRAS Y LINGÜÍSTICA

Martha Martínez Figueroa

COMItÉ EDITORIAL INTERNO

César Avilés Icedo

Rosa María Burrola Encinas

Fortino Corral Rodríguez

Leticia Martínez Figueroa

Jesús Abad Navarro Gálvez

Gabriel Osuna Osuna

María Rita Plancarte Martínez

DiRECTOR

Fortino Corral Rodríguez

Giuseppe Bellini

Universidad de Milán

Luis Beltrán Almería

Universidad de Zaragoza

Helena Beristáin

Universidad Nacional Autónoma de México

Raúl Bueno-Chávez

Dartmouth College

Evodio Escalante

Universidad Autónoma Metropolitana

Beatriz González-Stephan

Rice University

Aníbal González Pérez

Yale University

Aurelio González Pérez

El Colegio de México

Yvette Jiménez de Báez

El Colegio de México

Nelson Osorio Tejeda

Universidad de Santiago de Chile

\section{CONSEJO INTERNACIONAL}

Carlos Pacheco

Universidad Simón Bolivar

Rafael Olea Franco

El Colegio de México

Joan Oleza Simó

Universidad de Valencia

Julio Ortega

Brown University

Luz Aurora Pimentel

Universidad Nacional Autónoma de México

Susana Reisz

The City University of New York

José Carlos Rovira

Universidad de Alicante

Charles Tatum

The University of Arizona

Jorge Urrutia

Universidad Carlos III de Madrid

Emil Volek

Arizona State University 


\section{Índice}

\section{Artículos}

La ciudad fronteriza de Luis Humberto Crosthwaite en Estrella de la calle sexta e Instrucciones para cruzar la frontera

Martín Torres SaUchetT . . . . . . . . . . . . . . 9

Artífices y simuladores: el influjo de los medios masivos y la cultura popular en la literatura latinoamericana del siglo XX Amalia Franco Castaño . . . . . . . . . . . . . . . . . 27

“Teoría del túnel”: El pre-texto de Rayuela Margarita Díaz de León Ibarra . . . . . . . . . . . . . . 45

Metaficción hispanoamericana y crisis de la representación literaria del sujeto

Jesús Eduardo Oliva Abarca . . . . . . . . . . . . 61

Los refranes y los poemínimos: análisis de una relación intertextual

IsAbelle Pouzet . . . . . . . . . . . . . . . . . . . . . . . . 79

\section{Notas}

La ciudad como categoría estética e ideológica en Cartas de relación de Hernán Cortés y Grandeza mexicana de Bernardo de Balbuena Jesús Abad Navarro Gálvez . . . . . . . . . . . . . . . . . 99 
Hacia una hermenéutica estridentista: de la crítica romántica a la crítica de vanguardia

Alberto Rodríguez González . . . . . . . . . . . . . . . . 111

Casas de encantamiento y El espía del aire, de Ignacio Solares: la reflexión de la escritura

Alejandra Sánchez Aguilar . . . . . . . . . . . . . . . . . . 123

\section{Reseñas}

Gilberto Giménez. Estudios sobre la cultura y las identidades sociales. México: Conaculta/ITESO, 2007

Ana Lourdes Álvarez Romero . . . . . . . . . . . . . . . . . . . 135

Angélica Tornero. El mal en la narrativa de Inés Arredondo. México: Casa Juan Pablos/Universidad Autónoma del Estado de Morelos, 2008

Griselda Córdova Romero . . . . . . . . . . . . . . . . . . . . . . . 141

Guadalupe Fernández Ariza, coord. Literatura hispanoamericana del siglo XX. Historia y maravilla. España: Universidad de Málaga, 2006

Mayra Alejandra Borbón Espinoza . . . . . . . . . . . . . . 147

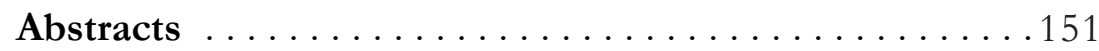

Résumés ... . . . . . . . . . . . . . . . . . . . . 157

Normas editoriales ..................... 163 
ConNotas. Revista De CRítica Y TEORía literaRias/AÑo VII, Núm. 12/2011

\title{
$\sim$ Notas $\sim$
}

La ciudad como categoría estética e ideológica en Cartas de relación de Hernán Cortés y Grandeza mexicana de Bernardo de Balbuena

\author{
Jesús Abad NAVArRo GÁlveZ*
}

Resumen:

Con una reflexión de la ciudad como categoría operativa en el análisis literario se abre la posibilidad de pensar de dos maneras distintas a la ciudad. Primero, desde la perspectiva que le da la panorámica como un todo, la ciudad aparece como la versión oficial de esa selva de construcciones organizadas racionalmente para poder ser manipuladas por los órganos de control. Desde la otra perspectiva, desde una enunciación peatonal, aparece la ciudad real, la que es espacializada por los recorridos de la anterior enunciación. Los ejemplos utilizados en relación a estas ideas son la "Segunda carta de relación" de Hernán Cortés y Grandez̨a Mexicana de Bernardo de Balbuena. Ambos hacen referencia a la ciudad de México en dos épocas distintas que distan un siglo una de otra.

Palabras clave:

Representación, Conquista, espacio, cosmos, textualidad.

\footnotetext{
* Universidad de Sonora.
} 
Una forma de acercarse a la relación que se establece entre literatura y ciudad es pensar en ésta como concepto y esperar de ella que sea una categoría operativa. Como concepto, la ciudad estaría ligada entonces a un fenómeno de lectura a través del cual la realidad compleja que la habita estaría organizada como un cosmos. A su vez, este fenómeno implicaría un sujeto que observa, que estaría implicado en un proceso de focalización, invitado a ver el todo desde una mirada consecuentemente delimitada: el ser humano. No obstante, este fenómeno no impide que se experimente un éxtasis de leer las partes como un todo y, por consiguiente, se incremente la certeza de lo que es representado por la ciudad, y a su vez se corra el riesgo de excluir otras perspectivas, ya que "ser sólo este punto vidente es la ficción del conocimiento” (De Certeau 104).

Esta situación de márgenes indefinidos cuestiona la autoridad epistemológica de la representación no sólo por el fenómeno de la parcialidad visual, sino también por la problemática política y cultural que implica la consideración de la época histórica que está delimitada en este trabajo. Aunque Grandeza Mexicana de Bernardo de Balbuena dista casi cien años de las Cartas de relación de Hernán Cortés, ambos textos están inscritos dentro de la problemática de la conquista y dominación del Nuevo Mundo. Lo que el peso del Otro significa a partir de este encuentro inaudito no sólo se deja ver en el terreno de los espacios conquistados, sino también en el ámbito epistemológico del enfrentamiento y convivencia entre dos culturas distintas. Las experiencias de este encuentro fueron textualizadas desde ambas perspectivas, pero desde ninguna de ellas se puede decir que fueran completamente representadas y categorizadas. Desde la perspectiva de los conquistadores, la experiencia de los referentes etnográficos del Nuevo Mundo tuvo un peso en el proceso de la representación, el cual fue proporcional a la actitud del autor de aceptar la experiencia de la otredad. Los límites de ésta dependían de la referencialidad intratextual, la cual obedecía a principios composicionales de la obra, y a la referencialidad intertextual, la cual evidenciaba la competencia textual del autor, ambas relacionadas con los intereses del productor textual. No obstante, esta interacción de referentes no estuvo exenta de fuertes 
tensiones internas y desequilibrios. En el siglo XVI, algunos eligieron solucionar esta problemática apelando a los logros que las artes plásticas habían conseguido, sobre todo en lo referente a la perspectiva, que había sido una conquista renacentista. Checa, citando a Erwin Panofsky, dice que "La perspectiva como un punto de vista inmanente, a la manera de un foco desde el cual se unifican las imágenes o escenas representadas" (19), es una idea análoga a la de leer una realidad por más compleja que sea como un cosmos, ordenada en un todo. No obstante esta resolución textual, hay que tener presente que la representación es una actividad textual que está ideológicamente mediada por los intereses del autor como productor textual.

En el caso específico del segundo texto de Cartas de relación, la visión de Hernán Cortés se desprende del carácter institucional con el que aquélla está estructurada. Tiene el deliberado propósito de informar, convencer y lograr fines concretos mediante el tratamiento de ciertos temas y el uso de ciertos recursos escriturales:

Más que a los detalles de la realidad física, presta atención a las instituciones sociales y políticas indígenas. Una de las principales características de la ciudad es la organización política que se infiere desde su estructura física. Es un signo aprovechado por Cortés para lograr la conquista. Cortés, por tanto, describe la ciudad desde esta perspectiva, para imponer el molde de las instituciones y costumbres españolas, pues el establecimiento de esas normas de civilización completaban la fase bélica de la conquista. (Checa 26)

Esto identifica la perspectiva de Cortés como la de una conciencia renacentista: natural y pragmática, convencida de la existencia de un orden armónico universal que no podía ser destruido por las contingencias inmediatas.

Uno de los principales fundamentos filosóficos de esta perspectiva es el nominalismo extremista que considera la realidad separada y valorativamente por encima de las ideas. Hay una sobrevaloración de la realidad, la cual produce una actitud de frialdad ante 
ella. Esta frialdad genera un desarrollo pragmático respecto a los objetos, de tal manera que culmina con la cosificación de estos. Se vuelven objetos con valor de utilidad, y sólo son importantes en cuanto tales. Son objetos que están desprovistos de vitalidad emocional propia. Un claro ejemplo de esta cosificación de la realidad natural lo muestra la descripción que hace Cortés de la ciudad de Tenochtitlán. Nunca deja que la impresión de algo nunca visto y tan grande y civilizado como lo hasta ese momento conocido influya en sus propósitos pragmáticos. La primera imagen que se tiene de la ciudad es desde una perspectiva estratégico-militar. Junto a la disposición geométrica de la misma, Cortés prevé lo que tendría que hacer en caso de que sufriera una traición por parte de los aztecas:

Esta gran ciudad de Timixtitan está fundada en esta laguna salada, y desde la tierra firme hasta el cuerpo de la dicha ciudad, por cualquiera parte que quisieren entrar a ella, hay dos leguas. Tiene cuatro entradas, todas de calzada hecha a mano, tan ancha como dos leguas jinetas. Es tan grande la ciudad como Sevilla y Córdoba [...] Y viendo que si los naturales de esta ciudad quisiesen hacer alguna traición, tenían para ello mucho aparejo [...] nos podrían dejar morir de hambre [...] luego que entré en la dicha ciudad di mucha prisa en hacer cuatro bergantines, y los hice en muy breve tiempo... (62)

Enseguida hace la descripción del mercado como el lugar en donde se puede encontrar de todo. Principalmente habla de los artefactos de metal como el oro, la plata y otros metales preciosos. Después pasa a enumerar todo tipo de animales y cosas que se comen. $\mathrm{Y}$ no se extiende en lo restante porque aduce no querer ser prolijo y por no acordarse de los nombres de lo que quiere mencionar, cuando seguramente no eran útiles tales descripciones para su objetivo. En tercer lugar, se menciona la plaza de Audiencia, lugar donde se resolvían asuntos de orden jurídico y social. Luego se habla de una de las principales construcciones en donde podría vivir fácilmente mucha gente. Se describen después los aposentos de estas construcciones con sus respectivos dioses incluidos en ellas. En 
esta parte, Cortés derriba el principal de ellos para poner a la Virgen Nuestra Señora, no mostrando en absoluto ningún respeto por los dioses locales. Más bien los reprueba aduciendo que son a ellos a quienes se les tributan sacrificios humanos. Luego habla de las casas de los ricos:

Hay en esta gran ciudad muchas casas muy buenas y muy grandes, y la causa de haber tantas casas principales es que todos los señores de la tierra, vasallos del dicho Mutezuma, tienen sus casas en la dicha ciudad y residen en ella cierto tiempo del año, y demás de esto hay en ella muchos ciudadanos ricos que tienen asimismo muy buenas casas. (64)

Finalmente, Cortés cierra la descripción de la ciudad mencionando las prácticas políticas de los señores que dependen de Moctezuma y su reino.

Cortés, como estadista y estratega militar, ve en Tenochtitlán una ciudad de una gran riqueza que puede ser optimizada por la Corona, pero que necesita de ciertos ajustes para lograrlo. Una de las principales acciones para lograr tal objetivo es presentar como relevante en la segunda carta la descripción de las formas de organización y gobierno que existen en el lugar, las cuales se convierten en objetivos urgentes a conquistar. Cortés se da cuenta de que al controlar estas formas de gobierno, consecuentemente, se puede tener acceso a los privilegios que se desprenden del tipo de riqueza que muestra en la descripción que hace de Moctezuma y sus costumbres, ya que todas ellas son producto del control que el gobierno de Moctezuma ejerce sobre las poblaciones de los alrededores. Otro ejemplo que evidencia esta mentalidad pragmática de Cortés que no permite contingencias dentro de una idea cerrada de orden es cuando deja ver la idea de totalidad que se desprende de la descripción que hace del mercado. Cortés no puede no haber percibido muchas más de las costumbres que explicita en su carta, por más extrañas que le hayan parecido, como los motivos de los sacrificios humanos. El punto es que no están incluidos en la carta porque eso implicaría un obstáculo para sus intereses de conquistar la ciudad 
de Tenochtitlán y de convencer a Carlos V de que el más indicado para hacerlos era Cortés mismo.

Vista así la descripción de la ciudad, se deja ver en ella una mentalidad que no acepta contradicciones. El mundo creado desde esta perspectiva se resiste a ser destruido por alguna contingencia inmediata. El proyecto escritural de Cortés intenta ejercer un dominio sobre la otredad, ajustando los medios a los fines, de modo que las enseñanzas del Príncipe de Maquiavelo se actualizan en los procedimientos, prácticos en su mayoría, del proyecto del autor de la segunda carta, ya que "repudia por inútiles ciertas especulaciones menos centradas en el verdad real de la cosa que en la representación imaginaria de la misma" (Checa 21). La ciudad desde esta perspectiva se convierte en una experiencia ideológica cuya construcción se transforma en un simulacro teórico visual, en el sentido de que la ciudad de México-Tenochtitlán es descrita en el marco de ciertos patrones conceptuales que no incluyen más que los detalles que están dentro de la idea preconcebida de totalidad de Cortés. Recuérdese cómo el mercado de Tenochtitlán es la dimensión representativa de esta idea de totalidad en el cual están "todas las cosas cuantas se hallan en toda la tierra" (66). Y el orden de cada una de las descripciones que Cortés hace de la ciudad que desea sojuzgar le facilita la legitimidad textual ante su destinatario de que el conquistador idóneo para llevar a cabo la proeza bélica de la conquista es él mismo.

Sin embargo, la ciudad-panorama que instala a un dios mirón que capta los detalles como un todo, metodológica y epistemológicamente se le escapa la actualización de las posibilidades y prohibiciones de los practicantes ordinarios de la ciudad:

Son prácticas cotidianas distintas a las construcciones visuales, panópticas o teóricas del espacio geométrico o geográfico. Son prácticas del espacio que remiten a una forma específica de operaciones (maneras de hacer), a otra espacialidad (tal vez antropológica, poética o mítica), y a una esfera de influencia opaca y ciega de la ciudad habitada. (De Certeau, "Andares" 105) 
A este respecto, las prácticas peatonales forman uno de estos sistemas reales cuya existencia crea efectivamente la ciudad, pero no son prácticas que tienen un lugar físico donde puedan ser encontradas. Son movimientos peatonales que no se localizan, sino que se espacializan.

Al preguntarle al texto de Cortés los cursos de sus motricidades peatonales realizadas después de haber descrito la ciudad de México-Tenochtitlán, para saber el curso peatonal de su proceder, ellas responden con una secuela de brotes bélicos que se alejan en gran medida no sólo de las muchas características de civilización que tiene la ciudad, sino de la relativa facilidad con que hace el recorrido hasta el centro de Tenochtitlán. Las escenas bélicas y desacuerdos recurrentes entre los principales jefes de conquistadores y aztecas tejen una parte de la ciudad a ras de suelo que hace experimentarla como un espacio de intereses encontrados no completamente identificados. Se visualiza el interés personal e imperial de Hernán Cortés por encima de los intereses de defenderla de los naturales de México-Tenochtitlán. Cortés tuvo algunas veces que modificar su proceder porque no le convenía. De modo que su retórica del andar por la ciudad se veía obligadamente modificada por las necesidades de sobrevivir y poder, en un futuro no muy lejano, apoderarse de la ciudad para liberarla de fanatismos religiosos y poder anexarla al proyecto imperial de la Corona española. Incluso él mismo narra cómo tuvo que huir para poder sobrevivir, lo cual es descrito como una situación circunstancial que no entorpece su proyecto de conquista. En otro momento, la Providencia misma sale en su auxilio cuando la lógica de los hechos bélicos apuntaba a una derrota inminente del ejército español:

Los cuales pelearon con nosotros tan fuertemente por todas partes, que casi no nos conocíamos unos a otros, tan revueltos y juntos que andaban con nosotros, y cierto creíamos ser aquel el último de nuestros días, según el mucho poder de los indios y la poca resistencia que en nosotros hallaban [...] Pero quiso Nuestro Señor mostrar su gran poder y misericordia con nosotros [...] hasta que quiso Dios que murió una perso- 
na tan principal de ellos, que con su muerte cesó toda aquella guerra. (85)

Aparecen discontinuidades en lo que venía sucediendo, las cuales de alguna manera indican ciertas prácticas que se salen del guión planteado por Cortés. Son los intersticios a través de los cuales se puede alcanzar a leer ciertos cursos peatonales que ilustran otras caras de la ciudad. Podría decirse que es posible leer dos tipos de ciudades en la segunda carta de relación de Hernán Cortés. Una de ellas es la que se construye a partir de las intereses imperiales de Cortés desde una perspectiva que explica cada una de sus partes como integrantes de un cosmos que busca implantarse en la recepción del destinatario de la carta (Carlos V); la otra, que contraviene la civilización dibujada en la descripción de la ciudad, la cual tiene que ser experimentada vía convenios y alianzas políticas que evidencian un sustrato de ciudad que no deja que se manifieste cabalmente, sino sólo su desacuerdo y problemática. Es una espacialidad medio agazapada por la imposición de una ciudad-botín hereje que hay que conquistar para la Corona española. Y como parte del continuum de la Reconquista, no puede no pensarse en el regreso de tiempos míticos, mejores que los que se vivían en los siglos XVI y XVII.

Casi cien años después de la Conquista de México por Hernán Cortés, Bernardo de Balbuena publica una carta-poema que lleva el nombre de Grandeza Mexicana. Esta carta está dirigida a Doña Isabel de Tovar, pariente lejana de don Francisco Gómez de Sandoval, Duque de Lerma, valido de Felipe III. En este texto se describe la capital virreinal de la Nueva España, y al mismo tiempo se instaura una de las primeras manifestaciones de literatura utópica en la lírica colonial hispanoamericana, si dentro de las acepciones de utopía se aceptan no sólo la de espacios que no existen pero que implican un bienestar, sino también de representaciones textuales que ilustran formas de ser y vivir que se vuelve imposible no aceptarlas inmediatamente. Si hay algo que la literatura ofrece al lector es la oportunidad de tener acceso a experiencias totales y completas que la vida cotidiana suele esconder. Este es el caso de Grandeza Mexi- 
cana, que realza las características más positivas de la ciudad de México. El argumento mismo del poema ilustra la totalidad de las virtudes mencionadas: "De la famosa México el asiento,/ origen y grandeza de edificios,/ caballos, calles, trato, cumplimiento,/ letras, virtudes, variedad de oficios, / regalos ocasiones de contento,/ primavera inmortal y sus indicios, / gobierno ilustre, religión y Estado,/ todo en este discurso está cifrado" (5).

La ciudad de México, en el poema, se convierte en la ciudad más rica y opulenta, la cual mantiene relaciones diplomáticas y comerciales con muchos países de los cuales sólo recibe lo mejor. Se habla de ella como de una ciudad llena de tesoros y bellezas en cantidad mayor "que de peces y arena el mar profundo;" también se le menciona como una ciudad que está libre de movimientos de insurrección, alejada de la guerra y en un momento de esplendor que se puede corroborar con sus construcciones y tipo de gente que la habita. Pero se dice que la mayor grandeza es un príncipe heroico, "a quien fortuna, si usara de razón, hiciera dueño de cuanto abraza el cerco de la luna."

Estas pequeñas muestras ilustran el tenor del poema y la utopía más allá de una visión de una realidad compleja organizada en un cosmos. Se opera un proceso de éxtasis de ver el conjunto como un todo, como si fuera un cuadro que tuviera implícito la posibilidad de pensar que se han olvidado y se desconocen las prácticas sociales que habitan las cotidianas calles de una ciudad: "! Oh ciudad rica, pueblo sin segundo,/ más lleno de tesoros y bellezas/ que de peces y arena el mar profundo" (72). Las mismas condiciones de una visión de la ciudad-panorámica son también las que impiden ver la ciudad a ras del suelo. Así que, aunque la ciudad virreinal ofrezca la oportunidad de descubrir en ella un cierto número de propiedades que pueden ser estables, aislables y articulables entre sí, en donde hay un gobierno imperial y monárquico que mantiene la paz en común acuerdo con la Iglesia, cuyo arzobispo es una estrella en el firmamento, y que las herejías son controladas por el Santo Oficio y la educación se imparte en las universidades, colegios y conventos, no obstante todo esto, decía, no puede no pensarse, por otra parte, que la administración de tal funcionalidad no 
está combinada con una eliminación de realidad que sobrevive al margen. Existe un proceso de organización y clasificación de las propiedades de la ciudad, en cuya funcionalidad hay una "diferenciación y redistribución de partes y funciones de la ciudad, gracias a trastocamientos, desplazamientos, acumulaciones" (De Certeau, "Los aparecidos" 144). Este tipo de organización rechaza lo que no es funcional y por ende se constituye en desechos que no desaparecen sino que o son utilizados coyunturalmente para ajustar las redes del orden o permanecen en estado liminal entre las fisuras de las propiedades estables, aislables y articulables de la ciudad:
Al fin, no hay tan estrecho o tan menudo oficio de primor y sutileza, de fuerzas grandes, o de ingenio agudo, que a esta ilustre ciudad y su grandeza no sirva de interés o de regalo, de adorno, utilidad, gracia o belleza. (54)

Así que, aunque el lenguaje del poder "se urbaniza," sigue existiendo ciudad fuera del poder panóptico de ella misma. Y es esta parte de la ciudad la que Balbuena deja oculta y no dice de ella acaso más que "no ha cien años que miraba en esto/chozas humildes, lamas y laguna; y sin quedar terrón antiguo enhiesto,/ de su primer cimiento renovada/ esta grandeza y maravilla ha puesto"(141). Una afirmación que contradice lo afirmado por Hernán Cortés en una cita anterior en la que describe las casas de los señores principales y en general de los ricos de Tenochtitlán.

La literatura de la época colonial respondía a las necesidades y funciones de la ciudad virreinal, la cual estaba orientada a mantener la estabilidad del imperio. Había un exceso de burocracia estatal y religiosa que mantenía la sociedad de castas en tres círculos concéntricos que tenían el objetivo de mantener sometida a la población, sin perder sus nexos con el poder virreinal. No hay que olvidar que la Corona necesitaba mucho dinero, el cual le era mandado de América, y como consecuencia tuvo que ceder a las peticiones de los encomenderos. Este es un ejemplo que evidencia el 
tenor de las relaciones de simulación que imperaban en la época: a cambio de este dinero, la petición de la Corona de la protección de los indígenas "se cumplía pero no se obedecía."

En este mundo de enmascaramiento, no podía no haber diferencias y tensiones. Sin embargo, lo que no funcionaba era parte de lo rechazado, que si bien algunas veces no era ni siquiera mencionado porque aparecía al margen, en otras se convertía en lo que debía ser desechado o superado para una mejor ciudad. Balbuena mismo deja entrever la dinámica de la vida cotidiana de la época:

Pida el antojo, el apetito tase...

Convites, recreación, conversaciones,

Con gente grave, o con humilde gente,

De limpias o manchadas condiciones;

Que en todo esta gran corte es eminente:

En juego, en veras, en virtud, en vicio,

En vida regalada o penitente.

En toda facultad, todo ejercicio,

Acomoda los medios a los fines,

O ya contrario al bien o ya propicio. (136)

No es posible evitar pensar que hay por lo menos dos ciudades que pueden leerse en los textos aludidos. En Cortés, la ciudad es construida desde sus intereses imperiales; una enunciación peatonal, sin embargo, muestra otra ciudad a ras de piso que convive con la del discurso masculino y heroico en la segunda carta de Cortés. Por su parte, Balbuena idealiza la ciudad de México, o más bien, prepondera en su discurso los anillos que a su discurso hegemónico le conviene que aparezcan. Pero desde ese olvido de las prácticas sociales a ras de piso que la visión panóptica que se tiene de la ciudad, no puede no estar atento el lector a construir imágenes de la ciudad real que liminalmente convive con la ciudad hegemónica del poema de Balbuena. Así pues, se podría concluir que la ciudad hegemónica del discurso oficial es una construcción predominantemente ideológica, mientras que la inclusión de la ciudad liminal a ras de piso proporciona una visión completa de la ciudad, favoreciendo la posibilidad de una percepción estética de la misma. 


\section{Bibliografía}

Checa, Jorge. Experiencia y representación en el siglo de Oro. Valladolid: Junta de Castilla y León/Consejería de Educación y Cultura, 1998. Cortés, Hernán. Cartas de relación. México: Porrúa, 1992.

De Balbuena, Bernardo. Grandeza Mexicana. México: UNAM, 1941. De Certau, Michel. "Andares de la ciudad." La invención de lo cotidiano I. Artes de hacer. México: Universidad Iberoamericana, 2000.

__ "Los aparecidos de la ciudad." La invención de lo cotidiano II. Habitar, cocinar. México: Universidad Iberoamericana, 1999.

Hauser, Arnold. "El dualismo del gótico." Historia social de la literatura y el arte 1. Barcelona: Editorial Labor, 1992.

Medina, Rubén "Masculinidad, imperio y modernidad en Cartas de Relación de Hernán Cortés." Hispanic Review 72.4 (2004): 469489. 